\title{
Cost-Volume-Profit Analysis as a Management Tool for Decision Making In Small Business Enterprise within Bayero University, Kano
}

\author{
${ }^{1}$ Sadiq Rabiu Abdullahi, ${ }^{2}$ Bello Abiodun Sulaimon, \\ ${ }^{2}$ Ibrahim Salihu Mukhtar, ${ }^{2}$ Muhammed Hardy Musa \\ ${ }^{1}$ Department of Accounting, Bayero University, Kano-Nigeria (srabdullahi.acc@buk.edu.ng) \\ ${ }^{2}$ M. Sc. Accounting, Bayero University, Kano- Nigeria
}

\begin{abstract}
This study aimed to figure out if small business enterprises utilize cost volume profit (CVP) analysis as a management tool for decision-making process in Bayero University Kano, with a view to shed light on the reality of the use of CVP analysis as a decision-making tool in small business enterprises. The study population is made up of the entire small business enterprises within Bayero University, Kano. Primary source of data were utilized using structured questionnaires. The hypotheses were tested using Mann-Whitney U test and Pearson correlation coefficient. A very weak relationship (0.02) was recorded, it was discovered that there is no statistical significant difference between having the knowledge of a management accounting tools and its application. The study concludes that small business enterprises utilize CVP ignorantly and it is recommended that CVP analysis and other management accounting tools be introduced to small business enterprises so that productivity can be improved.
\end{abstract}

\section{Introduction}

A business is an enterprise, or organization set up by an individual or group of individuals for the purpose of making profits from. Olagunju (2008) defines business as an enterprise that engages in the production of goods/services that provide satisfaction for consumers. Businesses in Nigeria range from micro, small and medium to large ones. The definition of small business differs from country to country and from industry to industry. Each country tends to derive its own definition based on the role small businesses are expected to perform in the development of the country. Definitions change over a period of time with respect to price levels, levels of technology, and other considerations. Small businesses are synonymous with small and medium scale enterprises (SMEs). SMEs are usually referred to as small businesses in developed countries

The existence of strong and effective small-scale industries has been considered as the best way to improve the socio-economic status of any society in large number of developed and less developed countries. There are excellent examples of government initiatives aimed at promoting and sustaining entrepreneurship development in small- scale industries (Adejumo, 2001). The main purpose is usually to reduce underdevelopment. Other underlying reasons include a desire to establish an enterprise culture; assist the disadvantaged section of the population; develop alternative to stagnation sector economy; reduce national dependence on imported goods; increase rural transformation; diversification of the economy and reduction of unemployment.

Earning of maximum profit is the ultimate goal of almost all business undertakings. The most important factor influencing the earning of profit is the level of production (i.e., volume of output). Costvolume-profit (CVP) analysis examines the relationship of costs and profit to the volume of business to maximize profits. There may be a change in the level of production due to many reasons, such as competition, introduction of a new product, trade depression or boom, increased demand for the product, scarce resources, change in selling prices of products, etc. In such cases management must study the effect on profit on account of the changing levels of production. A number of techniques can be used as an aid to management in this respect. One such technique is the cost-volume-profit analysis.

The term cost volume profit analysis is interpreted in the narrower as well as broader sense. Used in its narrower sense, it is concerned with finding out the "crisis point", (i.e., break-even point) i.e., level of activity when the total cost equals total sales value. In other words, it helps in locating the level of output which evenly breaks the costs and revenues. Used in its broader sense, it means that system of analysis which determines profit, cost and sales value at different levels of output. The cost-volume-profit analysis establishes the relationship of cost, volume and profits.

Furthermore, one of the most important decisions that need to be made before any business even starts is 'how much do we need to sell in order to break-even?' By 'break-even' we mean simply covering all our costs without making a profit. This type of analysis is known as 'cost-volume-profit analysis'. Cost-volume-profit 
analysis is a key factor in many decisions, including choice of product lines, pricing of products, marketing strategy, and utilization of productive facilities. It is a tool used to show the relationship between various ingredients of profit planning and if properly applied it enable the company to satisfy the industry and stakeholders of such business. This research work intends to look at cost volume profit analysis as a management tool for decision-making.

This study therefore seeks to know if cost volume profit analysis has any relevance when making decision in small business enterprise within Bayero University Kano. In developing countries like Nigeria, the role of SMEs is equally of strategic importance as they facilitate Indigenous entrepreneurship, reduce poverty and provide employment for a large number of people amongst other important roles that they play.

Although there are no clear statistics on the number, geographical distribution, and activities of the SME sector and the available statistics could be very partial and highly unreliable. The best estimates available suggest that SMEs comprise $87 \%$ of all firms operating in Nigeria, although the total number of registered firms in Nigeria is also unknown (World Bank 2002a, p.127). In another study conducted in Nigeria by the Federal Office of Statistics, it is estimated that over $97 \%$ of all businesses in Nigeria employ less than 100 employees. This therefore means that about $97 \%$ of all businesses in Nigeria are SMEs Ariyo (2000) as sighted in (Abereijo and Fayomi, 2005)

This study will assist small business enterprise managers and other professional who may find it useful to understand how to make better managerial decisions using cost Volume Profit analysis. It will also help academicians or student of knowledge who want to conduct further research on CVP analysis.

So many people run different business without any technical know-how or how to make decision that will affect their business positively. They nurture a dream to make profit from business and immediately venture into it within the university. It is on the bedrock of this that the study seek to find out the relevance of cost volume profit (CVP) analysis as a management tools for decision making in small business enterprise within Bayero University Kano.

This study focused on analyzing the relevance of cost volume profit analysis as a management tool for decision making in small business enterprise in general but with particular reference to small business enterprise within Bayero University Kano, Nigeria.

\section{Literature Review}

According to Ekpeyong \& Nyong, (1992), there is no universally accepted definition of SMEs because the classification of business into small and large scale is a subjective judgment. The main criterion employ in the definition of SMEs according to Carpenter (2003) could include various combinations of the following: Number of employees, financial strength, sales value, relative size, initial capital outlay and types of industry. In countries like the USA, Britain and other European countries, Small and medium scale enterprises are defined in terms of turnover and number of employees.

The definition and classification of SMEs in Nigeria is in terms of capital employed, turnover and number of employees. The CBN communiqué No 69 of the special monetary policy committee meeting of April 15, 2010 acknowledged the existence of several definitions of SMEs. One of such definition/classification states that an enterprise that has an asset base (excluding land) of between N5 million to N500 million and labour force of between 11 and 300 belongs to the SME sub-sector. This definition is what the Small and Medium Enterprises Credit Guarantee Scheme (SMECGS) adopted. SMEs have also been broadly defined as businesses with turnover of less than N100million, for the Small and Medium Enterprises Equity Investment Scheme (SMEEIS), a small and medium enterprise is defined as any enterprise with a maximum asset base of N1.5 billion (excluding land and working capital) with no lower or upper limit of staff. For the purpose of this study, small business enterprises are business with not less than two employees.

There exists close relationship between the cost, volume and profit. If volume is increased, the cost per unit will decrease and profit per unit will increase. Thus, there is direct relation between volume and profit but inverse relation between volume and cost. Analysis of this relationship has become interesting and useful for the cost and management accountant. This analysis may be applied for profit-planning, cost control, evaluation of performance and decision making.

Abdullahi (2015) describes cost volume profit analysis as an estimate of how changes in costs (Both variable and Fixed) sales volume, and price effect the company's profit. Adenji (2008) states that cost-volumeprofit analysis are predetermined costs, target costs or carefully pre planned costs which management endeavors to achieve with a view to establishing or attaining maximum efficiency in the production process. According to him, cost-volume-profit analysis is cost plans relating to a single cost unit. Because cost-volume profit analysis purports to be what cost should be, any deviation represents a measure of performance. The predetermined costs are known as cost-volume-profit analysis and the difference between the cost-volume-profit analysis and actual costs are known as a variance. Drury (2000) defines cost-volume-profit analysis as predetermined cost; they are cost that should be marred under efficient operating conditions. The cost-volume profit analysis may be 
determined on a number of bases. The main uses of cost-volume-profit analysis are in performance measurement, control, stock valuation and in the establishment of selling prices. Cost-volume-profit analysis is a target cost which should be attained. Cost- volume- profit analysis is the systematic examination of the interrelationship between selling prices, sales and production volume, cost, expenses and profits (Glautier \& Underdown, 2001). This definition explains cost-volume profit analysis to be a commonly used tool providing management with useful information for decision making. Cost volume-profit analysis will also be employed on making vital and reasonable decision when a firm is faced with managerial problems which have cost volume and profit implications. Cost- volume- profit analysis according to Hilton R.W (2002) is a mathematical representation of the economics of producing a product. The relationship between a products revenue and cost function expressed within the cost-volume-profit analysis are used to evaluate the financial implication of a wide range of strategic and operational decisions.

Lucey (1996) defined breakeven analysis as "the term given to the study of the inter-relationships between costs, volume and profit at various levels of activity". The term breakeven analysis is the one commonly used, but it is somewhat misleading as it implies that only concern is with that level of activity which produces neither profit nor loss the breakeven point although the behaviour of costs and profits at other level is usually of much greater significance. Because of this an alternative term, cost-volume-profit analysis or CVP analysis is frequently used and is more descriptive.

Underlying the operation of cost-volume-profit analysis is a principle which states that "at the lowest level of activity cost exceed income but as activity increases income rises faster than cost and eventually the two amount are equal, after which income exceed cost until diminishing returns bring cost above income once again. This principle describe cost-volume-profit analysis with curvilinear. Cost and revenue curves which thought theoretically sound lack practicability. Accountant found the need to bring in addition information relating to cost behavior and sales policy this was to ensure that practical model be develop out of this principles.

The followings are the underlying assumptions of cost-volume profit analysis according to Horngen et al (2006)

- The behavior and revenues is linear.

- Selling price is constant.

- All cost can be divided in to their fixed and variable element.

- Total fixed cost remains constant.

- Total variable cost is proportional to volume.

- Volume is the only drive of cost.

- $\quad$ Prices of production inputs (eg materials) are constant.

Other areas of application of the breakeven model (C-V-P).exist and these include equipment selection, make - or- buy decision, advertising programmes, choice of channels of distribution, and plant additions. These decisions are the essence of planning and control. No doubt product planning and control in manufacturing firms is a necessity and can be facilitated and improved upon by breakeven analysis.

Other management accounting decision tools that can be used in making business decisions among small business enterprises includes; Activity based costing, Make or Buy Analysis, Budgets, Product costing, Variance analysis, Economic Ordering quantity (EOQ), Decision theory (decision tree), among others.

\section{Empirical Review}

Practical applications of Cost-Volume profit analysis often give rise to series of questions both at the tactical and strategic management level. Ihemejea, Okereafor, \& Ogungbangbe (2015) found out that costvolume-profit analysis is considered to a large extent in the decision making process of manufacturing industries and hence affect the various decisions made by manufacturing industries. It was also found these manufacturing industries adopt both graphical and algebraic approaches to cost-volume- profit analysis. The study further revealed that the application of cost-volume profit analysis techniques in decision making process to a very large extent enhance managerial efficiency of manufacturing industries. In addition it was revealed that the benefits derived from the application of cost-volume-profit analysis include: efficient cost control, high productive capacity and increase in profitability.

Georgiev (2014) studied the Application of 'Cost-Volume-Profit' Analysis in the Hotel Industry based on survey data of high-ranking hotels in the north-east region of Bulgaria, research results indicate that analysts apply the CVP analysis to all aspects of management accounting, which clearly speaks of its significance for generation of data on hotel management. Taking into account the specifics of the hotel product we cannot but accept as logical the results on the extent and frequency of application of CVP analysis.

Consequently, Nabil, Osama, \& Zaid (2014) while looking at the effect of using break-even-point in planning, controlling, and decision making in the industrial Jordanian companies concluded that, the most of the Jordanian industrial companies are using break-even point in the planning, controlling and decision-making, and 
there is a statistical significant relationship between the use of the break-even point and successful planning, control and decision-making in the Jordanian industrial companies.

Corroborating the study by Ndaliman and Bala (2007), Onwuka (2009) suggests a thorough application of breakeven analysis to improve profit levels of small manufacturing firms. She (Onwuka) further states that the mathematical involvement was little, while the advantage was enormous. Most managers are too afraid of figures; they would find this method a safe- landing. Ndaliman and Bala (2007), in a related study discovered that "sales revenue and total cost were not linear, two or more breakeven points were found to exist, some costs fall under both fixed and variable portions and that beyond certain optimal production levels sales revenue decreases and total cost also increases. They suggest that block industry operators because of the short pay back period of the investment and rising profit levels when efficiently managed using breakeven tool of analysis should adopt breakeven theory frequently. Although they found slight variation in the principles of breakeven theory between the two industries studied, they emphasise adequate production planning and control using breakeven theory

\section{Methodology}

The study was conducted using the survey approach. The area of study was Bayero University Kano, which was choosing because it has a growing cluster of small business enterprises. Primary source of data was utilized using structured questionnaires. The hypotheses were tested using Mann-Whitney U test and the Pearson correlation coefficient

A total of 144 small business enterprises was physically counted [18(13\%) at old site and 126(87\%) at new site], given the small number, the total population was selected. Out of the 144 questionnaires distributed, $123(85 \%)$ was returned and accurately filled, $13(9 \%)$ was invalidated while $8(6 \%)$ shop owners decline to participate in the study.

\section{Demographic distribution of respondents}

\section{Data Analysis}

Majority of the respondents $(79 \%)$ are located at the new campus this is due to the fact that the new campus have most of the faculties and as such more business activities takes place in the new campus compared to the old campus of the university. Result shows that $85 \%$ of the respondents are male while only $15 \%$ are female (fig 1.2); $61 \%$ of the business enterprise had been in existence for over five years, while $25 \%$ are between two to five years and only $14 \%$ are below two years (fig 1.3). Most of the business owners, $49 \%$ are student currently undergoing a degree in the university while $15 \%$ are seeking admission into the university while running their business (fig 1.4).

Fig 1.1: Distribution of Respondents in term of Location

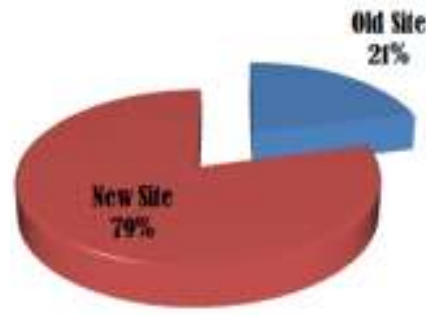

Fig 1.3; Year(s) in Business

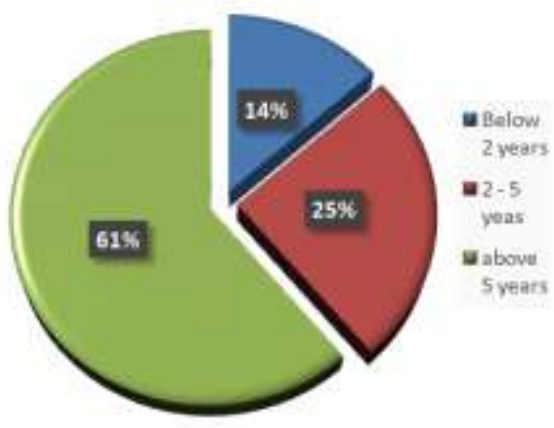

Fig 1.2; Respondents Distribution in term of sex

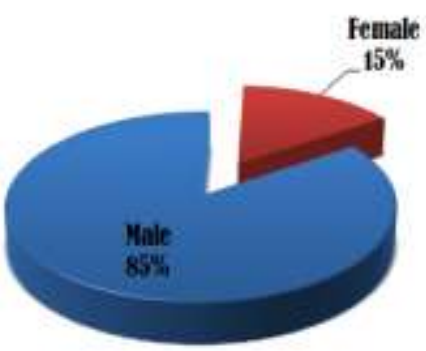

Fig 1.4; Education Status

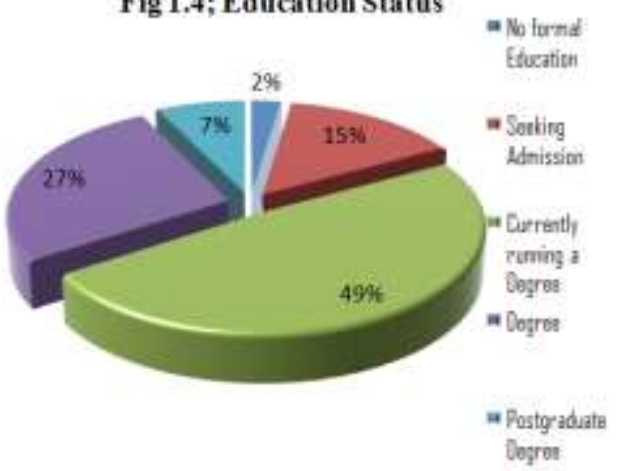




\section{Discussion of Findings}

$\mathbf{H o}_{1}$ : There is no significant relationship between having knowledge of CVP analysis and its application as a management accounting tools among small business enterprise in Bayero University, Kano.

Giving a P value of 0.798 , at 0.05 level of significant, we fail to reject the null hypothesis and conclude that there is no statistical significant relationship between having knowledge of CVP analysis and its application as a management accounting tools among small business enterprise in Bayero University, Kano.

Though a relationship was established, it was a very weak one (i.e. 0.1$)$ and not statistically significant. This implies that most of the small business enterprise in Bayero University, Kano have been unknowingly applying CVP analysis in making management decisions. This is however in contrast with the findings of Nabil, Osama, \& Zaid, (2014) who concluded that there is a significant statistical relationship between Break-EvenPoint and decision making in the Jordanian Industrial companies.

Table 1: Pearson Correlations coefficient

\begin{tabular}{|l|l|l|}
\hline $\mathbf{H o}_{2}:$ & Pearson Correlation & $\begin{array}{l}\text { P value } \\
\text { (95\% confidence) }\end{array}$ \\
\hline $\begin{array}{l}\text { There is no significant relationship between having knowledge of CVP analysis and } \\
\text { its application among small business enterprise in Bayero University, Kano. }\end{array}$ & 0.024 & 0.798 \\
\hline
\end{tabular}

$\mathbf{H o}_{2}$ : The awareness of CVP have no significant difference with its application among small business enterprise in Bayero University Kano

The Mann-Whitney U test yielded a p-value of 0.792, at 0.05 level of significance, this suggests that no significant difference exists between awareness of CVP analysis and its application. We therefore fail to reject the null hypothesis and concludes that awareness of CVP have no significant difference with its application among small business enterprise in Bayero University, Kano.

This shows that CVP analysis can be applied in small business enterprises, this is in line with the submission of Ndalima and Bala (2007) and the assertion of Levin et al (1999) and Nweze (1992). These studies indicate that B./E or C.V.P is applicable in many situations. It was found that the application of B./E analysis in making business decision enhances profitability of the firm.

Table 2: Mann-Whitney U test

Hypothesis Test Summary

\begin{tabular}{|c|c|c|c|c|}
\hline & Null Hypothesis & Test & Sig. & Decision \\
\hline 1 & $\begin{array}{l}\text { The distribution of Application of } \\
\text { CVP is the same across categories } \\
\text { of Awareness of Management acct } \\
\text { tools. }\end{array}$ & $\begin{array}{l}\text { Independent- } \\
\text { Samples } \\
\text { Mann- } \\
\text { Whitney U } \\
\text { Test }\end{array}$ & .792 & $\begin{array}{l}\text { Retain the } \\
\text { null } \\
\text { hypothesis }\end{array}$ \\
\hline
\end{tabular}

Asymptotic significances are displayed. The significance level is .05 .

\section{Conclusions and Recommendations}

Findings suggest that there is no significant difference between the application and awareness of CVP analysis, most of the small business enterprises ignorantly applied cost volume profit analysis in the course of doing their business, without knowing that the managerial decisions they took most times is related to cost volume profit analysis. It was also shown that small business enterprise can apply cost volume profit analysis to great advantage as it aids the management decision making process.

Based on the above conclusions, it was recommended that cost volume profit analysis and other management accounting tools be introduces to small business enterprise in other to improve their productivity. Managers of small businesses should utilize the advantage of being situated in an academic environment to attend a crash course on cost volume profit analysis and other management decision making tools to broaden their scope in other to make better management decisions. 


\section{References}

[1]. Abereijo and Fayomi (2005): Innovative Approach to SME Financing in Nigeria: A Review of Small and Medium Industries Equity Investment Scheme (SMIEIS ) J. Soc. Sci., 11(3): 219-227 (2005)

[2]. Abdullahi, R. S. (2015). Mastering Cost and Management Accounting.(3rd ed) Kano: Sharif Mahir Investment Ltd

[3]. Adejumo, G. (2001). Indigenous entrepreneurship development in characteristics, problems and prospects. Journal of Department of Business Administration, University of Ilorin, Ilorin Nigeria., 112-122.

[4]. Adeniran, Y. A. (2001). Introduction to Engineering Economics. Minna: Fuin Association.

[5]. Adeniyi, A. A. (2008). An Insight into Management Accounting (4th ed.). Lagos, Nigeria: El - Toda Ventures Limited.

[6]. Amrine, H. T., Ritchrey, J. A., \& Hully, O. S. (1983). Manufacturing Organisation and Management (4th ed.). New Delhi: Prentice Hall of Indian Private Ltd.

[7]. Ann, I. O., Christopher, C. O., \& Adibe, T. N. (2012). Improving Production Planning and Control through the Application of Breakeven Analysis in Manufacturing Firms in Nigeria. Industrial Engineering Letters , 2(No. 6). doi:ISSN 2224-6096

[8]. Berryman, C. W., \& Nobe, M. D. (1999). Practical Business Application of Breakeven Analysis in Graduate Construction Education. Edinburgh: J. Crust.

[9]. Carpenter, C. (2003) "SME Finance in Nigeria". Paper presented to the Roundtable on "Making Small Business Finance Profitable in Nigeria". Access at http://www.ypforum.org/newsCarpenter.

[10]. Colin, D. (2008). Management and Cost Accounting. . London: .Booking Power Publishers.

[11]. Ekpeyong, D.B. and Nyong, M.O. (1992) "Small and Medium Scale Enterprises Development in Nigeria". Seminar Paper on Economic Policy Research for Policy Design and Management in Nigeria, NCEMA.

[12]. Georgiev D. (2014), Application of 'Cost-Volume-Profit' Analysis in the Hotel Industry (Based On Survey Data Of High-Ranking Hotels In The North-East Region Of Bulgaria). Journal of University of Economics Varna 48 Econ Lit

[13]. Glautier, M., \& Underdown, B. (2001). Accounting Theory and Practice. Harlow England: Pearson Education Limited.

[14]. Hilton, R. W. (2002). Management Accounting Creating Value in a Dynamic: Business Environment. . Irwin: McGraw Hill .

[15]. J.Ihemejea, J. C., Okereafor, G. B., \& Ogungbangbe, B. M. (2015, November). Cost-volume-profit Analysis and Decision Making in the Manufacturing Industries of Nigeria. Journal of International Business Research and Marketing, 1(1). doi:10.18775/jibrm.1849-8558.2015.11.3001

[16]. Lewin., R. (1999). Production /Operations Management: Contemporary Policy for Managing Operating Systems. Cambridge: Harvard University Press.

[17]. Lynn, H. B. (1999). Production Planning and Control and Cost Accounting Systems: Effect on Management Decision Making and Firm Performance. New York: Free Press.

[18]. Nabil, A., Osama, S. S., \& Zaid, A.Z. (2014). The Effect of Using Break-Even-Point in Planning, Controlling, and Decision Making in the Industrial Jordanian Companies. International Journal of Academic Research in Business and Social Sciences, 4(5). doi:10.6007/IJARBSS/v4-i5/888

[19]. Ndaliman, M. B., \& .Bala, K. C. (2007). Practical Limitations of Breakeven theory.

[20]. Nvachukwu, C. C. (2004). Management Theory and Practice. Onitsha: Africana Fist Pub. Ltd.

[21]. Olagunju, Y.A. (2008). Entrepreneurship and Small Scale Business Enterprises Development in Nigeria. Ibadan: University Press PLC

[22]. Pollack, B. (1995). Breakeven Analysis; The Third Leg of the Underwriting Stool. Real Estate Review, 25.

[23]. Powers, L. (1987). Breakeven Analysis with Semi Fixed cost. Journal of Industrial Market Management, 67(8).

[24]. Sinclar, K., \& Talbot, J. (1986). Using Breakeven Analysis When Behaviour is Unknown. Journal of Management Accounting, $68(1)$ 